\title{
Some Aspects of Australian Universities for Chinese Universities to Consider
}

\author{
Wang Yong Yin ${ }^{1,2, ~ *, ~ T a h e r i ~ A b b a s ~}{ }^{2}$, Liu Ping ${ }^{1,3}$, Pan Qi Zhi ${ }^{1}$ \\ ${ }^{1}$ Mining College, Guizhou University, Guiyang, China \\ ${ }^{2}$ School of Civil Environmental and Mining Engineering, University of Adelaide, Adelaide, Australia \\ ${ }^{3}$ School of Earth Science, University of Queensland, Brisbane, Australia
}

Email address:

yywang2@gzu.edu.cn (Wang Yong Yin), abbas.taheri@adelaide.edu.au (T. Abbas)

${ }^{*}$ Corresponding author

\section{To cite this article:}

Wang Yong Yin, Taheri Abbas, Liu Ping, Pan Qi Zhi. Some Aspects of Australian Universities for Chinese Universities to Consider. Education Journal. Vol. 6, No. 3, 2017, pp. 110-115. doi: 10.11648/j.edu.20170603.11

Received: March 28, 2017; Accepted: April 11, 2017; Published: April 28, 2017

\begin{abstract}
Several universities in Australia and in western China were investigated and compared together. Different aspects including equipment and facilities, arrangement of office and arrangement of laboratory, class scheduling, relationship between staff and students were considered to investigate differences between western Chinese and Australian universities. These parameters being investigated are seemingly trivial, subordinate and seldom been noticed by the public but it can quickly and greatly influence the humanity environment of campus and academic atmosphere. To do this study, Chinese economic factors and custom environment that caused these differences had been analyzed. Finally, it is pointed out some aspects of Australian universities that might be useful to be implemented in Chinese universities.
\end{abstract}

Keywords: Investigation, University, Australia, Western China, Merits Analysis

\section{Introduction}

Education in Chinese university is very different from most of developed countries. Although with recent great improvements in the past ten years, the gap is reduced considerably. By looking at number of Chinese universities and Australian universities among top 100 universities, introduced by QS World University Rankings, the differences is still very obvious. There are 43 accredited universities in Australia comprising 40 national universities, two international universities, and a small private university. Higher education courses and qualifications are also offered by many non-university providers in the higher education sector [1]. According to QS World University Rankings (2016-2017), there are six universities of Australia ranked in the top 100 universities [2]. However, date to May 30, 2016, there is a total of 2879 higher education institutions in China including 284 universities or institutes of continuing education for adult [3], but there are only four universities listed in the top 100 of QS World University Rankings (2016-2017) [2]. In other words, $13.95 \%$ of Australian universities ranked in the top 100 of the world while only $0.14 \%$ of Chinese universities listed in the top 100 of the world in QS World University Rankings (2016-2017).

Supporting Chinese university instructors to visit universities in other countries is one of the various measures to improve the education of China. The new Chinese government has realized that the quality of university instructors is one of the critical factors, which influenced the development of university education. Supporting Chinese university instructors to visit universities in other countries is an important approach of professional development. It had been incorporated into a comprehensive university instructor's development package for Chinese university [4]. In this respect, China Scholarship Council (CSC) was established in 1996 to take responsibility for merit-based selection and to fund Chinese academics to visit foreign universities. The CSC is now encouraging more university teachers to study abroad to improve the education of university. For example, in 2016, the CSC planned to fund 29000 people to study abroad, among them 10250 people would be university instructors [5]. This can be funded 
through visiting scholar and senior visiting scholar programs or young "backbone" programs for university instructors or the West Region of China programs for university instructors. By contrast, the CSC planned to fund 21,350 people to study abroad in 2014, among them only 7700 people would be university instructors [4].

Chinese universities benefits significantly from sending their academics to study abroad. Lots of university instructors who studied abroad coming back to China have achieved various outcomes since the Chinese government began to fund university faculty to study abroad in 1955 [6]. Some of the outcomes are the overseas experiences of Chinese visiting scholars [7], some are the implications of visiting scholar programs for university instructors development in Chinese universities [8], but mainly the outcomes are academic achievements [9], such as research projects and papers collaborated with foreign tutor. Through studying abroad, the professional development, academic achievement and capability of writing and speaking in English of university teachers had achieved great improvement, which also had grabbed so much attention from the public [10-12].

Through analysis, there are some other advantages of Australian universities which can be considered by Chinese universities, such as equipment and facilities, arrangement of office and arrangement of laboratory, class scheduling, workplace environment and so on. These parameters have been investigated in several universities in Australia and in western China. It is believed that making some modification in the above parameters can quickly and greatly influence the structure of campus and academic culture and atmosphere in western Chinese universities [13]. Thus, this article excluded the professional development, academic achievement, capability of writing and speaking in English of university instructors and the differences in fundamental research between the universities of developed countries and China. Namely, this paper only focuses on infrastructure and structure of campus, classroom and laboratory and workplace environment based on the experiences of few visiting scholars at different universities in Australia.

\section{Some Differences between Australian and Chinese Universities}

The universities selected as the object for comparison from Australia are members of Group of Eight (Go8) and/or other ordinary higher education universities, from China are members of Project 211 (some of them are members of Project 985) and/or other ordinary national/provincial higher education universities.

It is worth mentioning, Group of Eight (Go8) is a coalition of research-intensive Australian universities. The Go8 universities are some of the largest and the oldest universities in Australia. Several Go8 universities, along with the University of Tasmania, are called the Sandstone or Brick universities [14].

Project 211 is the Chinese government's national initiative that aims to strengthen approximately 100 institutions of higher education and prioritize their development for the $21 \mathrm{st}$ century. There are a total of 112 institutions under the project [4].

In addition, project 985 was an endeavor to build top-ranking Chinese higher education institutions into world-class universities. It was launched on May 4, 1998 by the President Jiang Zemin, and has a total of 39 universities, which are also part of Project 211 [4].

\subsection{Classroom Equipment}

There are some aspects of multi-media classroom in Australian university that are more advanced than those of western China.

Some Australian universities are using smart boards [15] which are very useful educational tool. Teachers can write on the smart board just like writing on the blackboard, which overcome the disadvantages of writing on the screen or PPT even on black or white board. However, in China, neither Project 211 nor the others or even in Project 985 of western China, smart board has not been implemented in multi-media classroom.

Secondly, almost all Australian universities are using document cameras. Document camera is used to display images, text, and three-dimensional objects. The video signal from the document camera is routed to the LCD Projector. Teachers can perform some complicated formula on papers step by step in hand while students can see all the procedure to derive the formula. The handwriting of teachers will be shown on the screen through a video projector. Meanwhile, the PPT of the computer can be transferred to another screen through a data projector. This is more suitable to illustrate different engineering concepts. These facilities can be found in most of Australian universities [14]. However, universities in western China are not equipped with these facilities.

Thirdly, desks and chairs with wheel and moveable legs can be found in most of the multi-media classroom of Australian universities. Several desks can be easily put together and form a circle table so that students can discuss something face to face. That's to say, the same classroom can be used for both lecture and seminar. It is an example of multiple usage of resource in Australian universities. It can enhance the utilization efficiency of infrastructure. However, in western Chinese universities, both Project 211 and Project 985, almost all the desks and chairs are fixed on the floor. Thus, it only can be used as a teaching room but not suitable for seminar or tutorial.

Fourthly, wireless microphone (lapel microphone) is another good example with more humanism design, which is more suitable for the teachers who need to walk around the room. In Australian universities, every classroom has a wireless microphone. It facilitates the teacher to communicate with students. However, in some universities of western China, even in some project 211, except for that of project 985, there is only one gooseneck microphone (table top microphone) fixed on the podium very lowly. Even if teachers stand nearby the podium, they have to hold it in hand and put it close to their 
mouth in order to increase voice volume. When they walk to the opposite of the screen or of the podium, the gooseneck microphone needs to be put down because there the wire is not long enough.

Additionally, in Australian universities, different walls of the classroom have white board. It is suitable for teacher to write something when he is roaming away the integrated digital podium.

However, not all classrooms are equipped with modern equipment in Australian universities. For example, there are some multi-media classrooms only equipped with computer, projector and screen, and combining with some chairs with a board connected to hinges without desks because they are only used for liberal lecture.

As mentioned previously, the equipment of multi-media classroom may be very expensive for western Chinese university. However, the issue of finance shouldn't be a problem in high education, which is supposed to be priority one for a country, especially for Project 211 and Project 985.

\subsection{Effective Arrangement of Office Space}

The arrangement of office is not only equal to all staff but also efficient to the usage of limited resources.

The most important aspect of most Australian universities is that every academic staff has a shared or private office. Even if a visiting scholar could have shared office. The office of academic staff has been furnished with a white board close to a round table with several chairs also including a big desk for teacher. There are several advantages about this arrangement. Firstly, according to the nature of academic work, a private office with a big desk is suitable for the academic staff to study or learn in his office. Secondly, the round table with several chairs is suitable for tutorial when it is for not too many students, for example $\mathrm{PhD}$ students. Therefore, such an arrangement of office, on one hand it can reduce the requirement of classrooms, on the other hand it is suitable for teachers to learn and study.

In comparison with some western Chinese universities of Project 211, the situation is quite different. On one hand, only professor can enjoy a private office furnished with several sofas and a very low tea table to interview visitors. On the other hand, all the other academic staff only can share a meeting room with a big round table in the middle.

The other important aspect of most Australian universities is that all school officers share a big office. Considering the nature of administrative work, shared office, in general, is more suitable for administrative activities, as mainly staff should deal with students and take care of academic needs. However, in western China, almost every school officer or administrator has a private office. For instance, in a school of a western Chinese university of Project 211 with about 70 teachers and 15 school officers, all the school officers and administrators occupy the whole floor of the school building.

In Australia, the most efficient usage of limited office is that there is no special meeting room for the staff in one of the Go8 except for some multi-media classroom in the school building. When necessary, a classroom can be used as meeting room.
Comparing with the universities in western China, there are plenty of meeting rooms available without much usage. For example, in a western university of Project 211, a school with about 70 academic staff and 15 school officer has a very large meeting room, a big meeting room, a reception room and a small meeting room for administrator. Additionally, there are another five big meeting rooms for each research group. All of the big and small meeting rooms whether it is for the administrator staff or for other purposes are equipped with a big round council board and plenty of luxury chairs. Most of them are not used often because they are not specifically designed for academic usage purpose. These luxury-meeting rooms cannot be used for teachers or tutors for educational purposes.

The most convenient aspect is that each school of every Australian university has canteen or café bar furnished with microwave, refrigerator, dish washing machine, coffee machine, desks, sugar, tea, milk, water and so on for staff and students to use at any time. Such facilities make it very convenient for staff to have lunch and leisure time.

\subsection{Efficient Usage of Laboratory Space and Equipment}

In Australia, laboratories not only are used to do experiments but also are used for study and seminar especially for $\mathrm{PhD}$ students. This is the main feature of laboratories in Australian universities. For example, in some of laboratories of Go8 universities in Australia, all the equipment or apparatus are placed close to the walls to leave some place to have desks in the center, or vice versa. Sometimes there are several rooms available for $\mathrm{PhD}$ students to use for study. With this arrangement, academic staff or $\mathrm{PhD}$ students can easily do some experiments or do other research activities in the lab. As a result, laboratory space can be used effectively.

However, the laboratories of a member of Project 211 in western China are locked most of the time. Sometimes there may be a desk in it for the lab assistant to use. If an academic staff or a $\mathrm{PhD}$ student needed to do some experiments in one of the labs, they should book it with the lab assistant in advance. Otherwise, they won't be able to have access to the labs. In this case, some academic staff would rather pay some money for the labs in other universities or institutions to do experiments than to do experiments in their universities' lab.

In Australia, the advantage of setting several desks in lab is very obvious. On one hand, not only it provides students with a good space to study but also it is convenient for students to do some experiments. On the other hand, it is easy for academic staff to access the lab and will help them to use the lab equipment effectively.

\subsection{Effective Timetable}

The most significant advantage of timetable in Australia universities is that it can facilitate full usage of classrooms in working days. From 9:00am to 5:00pm, there are lectures or tutorials for students, which can take full usage of the classroom during daytime. In this case, students and teachers do not need to go to universities every day. Especially, it is 
good for those who live far away from the school. However, in western China, most of the universities have no class from $12: 00 \mathrm{pm}$ to $2: 00 \mathrm{pm}$ (in winter semester) or from $12: 00 \mathrm{pm}$ to $2: 30 \mathrm{pm}$ (in summer semester). That is to say, all classrooms are vacancy at noon except for a few students reviewing their lessons there. Furthermore, sometimes the school manager of the university in western China has to arrange some classes in the evening even during nighttime due occupancy of classrooms during daytime. In this case, teachers may have to wait several hours till the afternoon or evening to have their lectures. It is very inconvenient for lecturers who live outside the campus especially for those who don't have office space.

In Australian universities, there is not any reminder bell for break exists during class time, therefore the teachers can complete their lectures continuously without any disturbance.

\subsection{Friendly Workplace Environment}

In Australian university, people mostly are called by their first name regardless of their position and age. This may create friendly workplace environment. Using first name as address without administrative or academic position can fully embody the equal spirits. Address is a very common thing, but it is the implication about the principal of interacting and equal interpersonal relationship.

In Chinese universities, workplace culture is different and academic staff is called by their family name plus their administrative or academic position. This may create distance between staff to some extent. This is not to say that this kind of address is very incongruous everywhere. For example, in military, it is very necessary. Because all subordinates should absolute obedience to the superior, because obedience is the first duty of a soldier. Thus the cultivation of the concept of rank should do from daily life. But it is inappropriate in university campus, because what is needed in university campus is individual orientation, emphasis on freedom of speech, equality, innovative idea. Address with administrative or academic position hinders the cultivation of equality.

\section{Some Reasons for the Differences between Two Educational Systems}

From the previous discussion, it can be seen that most of them are seemingly trivial and subordinate, but changing them can quickly and greatly influence the campus humanities environment and academic atmosphere. But what caused these differences?

\subsection{Workplace Environment}

The most important factor is workplace culture. In China, sense of social hierarchy have a deeply influence on the daily life. For example, only administrator, officer and professor can enjoy a private office. Only authorized academic staff can access to labs. There are too many meeting rooms with big council table as well. Also, people like to be addressed with administrative or academic positions. All of these are due to the sense of social hierarchy. Thus, at present, some aspects of the university structure is the embodiment of power and status, and being respectful to authorities.

There are some other factors causing all the differences between Australian and western Chinese universities. Such as the former focuses on practice, interest, personality and equality while the latter focuses on respect and power. But all of these are caused by the sense of social hierarchy.

In that context, firstly, most of the sense of power and status should be reduced or erased in order to enhance the awareness of equality and justice, the sense of equality and harmonization should be cultivated. For instance, administrator and officer can share an office. Laboratory should be open to every academic staff during working days. Most of the meeting rooms should be converted to office space for academic staff. Utilization of the university resources should be improved.

Secondly, cultivate friendly workplace environment. Advocate directly using first name as address in daily life.

Thirdly, it is a good idea to create an equal opportunity environment as Australia does under the protection of law. Probably, this can guarantee the development of an equal and harmonious environment.

\subsection{Economic Factors}

Lack of financial support is the main reason for the backward of infrastructure. For instance, in a new campus of Australia, the classroom can be equipped by some modern equipment. While in a new campus of western China, the classroom can only be equipped by some basic equipment. If there is plenty of money for the construction of universities in western China, the multi-media classroom and lab would be more modern and more efficient.

Effective use of investment is a good way to overcome the lack of finance support. Chinese universities especially the western Chinese universities improve the way they practice to spend their budget, especially when limited funding is allocated by the government.

\subsection{Enrollment Rate}

Expanded enrollment rate in institutions is much faster than the growth rate of investment in recent tens of years. Under the guidance of the document issued by Ministry of Education of the People's Republic of China-Action plan for the promotion of education in twenty-first century, higher education should be popularization [16], then college enrollment increased by 400 thousand people per year, university freshmen rose to 6.75 million in 2011 from 1.08 million in 1998 when higher education yet not been expanded $[17,18]$. However, the per capita expenditure budget of university students in 2005 decreased $22.65 \%$ of that in 1998 . Moreover, students studying in universities increased 358\%, the per capita finance investment and expanded enrollment of higher education is on the opposite trend [19]. Because of the expanded enrollment of higher education in China, enrollment in institutions is faster than the growth of resources, downtrend students' average possession of resources, the 
expanded enrollment rate in institutions may adversely affect in the quality of Education [20].

Therefore, harmonizing the rate of enrollment and investment is another method to improve the quality of education.

\section{Dialectical Analysis}

As mentioned above, there are some advantages of Australian universities which can be used as references in western Chinese universities. But everything has its pros and cons. Not all aspects of Australian universities are better than that of Chinese universities.

For example, timetable of Australian university is more suitable for teachers and students. It can full use the classrooms and facilitate teachers and students to arrange their time, but no noon break time will incur some inconvenience for students or teachers if the timetable has designed with carelessness. For instance, if a teacher or student has been arranged to take part in a lecture from 11:00am to $12: 00 \mathrm{pm}$, and then take part in a tutorial from $12: 00 \mathrm{pm}$ to $2: 00 \mathrm{pm}$, then the student or the teacher will have no time to have lunch. It is not very healthy. Thus the school manager should arrange these two time sections for different class and different teacher so that they can have some time to have lunch.

As another example, no reminder bell for break during lecture interval is suitable for teachers who want to continue his unfinished subject. However, some disadvantages are not avoidable. For instance, some lectures may not finish on time, resulting other students and teachers waiting a long time outside the classroom.

\section{Conclusions and Suggestions}

Through the analysis of the existence differences between Australian universities and Chinese universities and the analysis of reasons which caused these differences, In order to improve the education quality of western Chinese universities, the most important factors which should be considered are as follow:

1) Cultivate friendly workplace environment for talent cultivation and academic research, Emphasize on freedom, equality and creative ideas.

2) Overcome the unreasonable influence from some aspects of custom; abandon the idea of excessive exaggeration of power, respect and so on.

3) Increase investment especially in infrastructure such as equipment of multi-media classrooms, office and laboratories.

4) Efficient use of existed facilities include multi-media classrooms, office and laboratories, focus on humanity care of faculty, as well as design timetable tailored for teachers and students.

5) Harmonize the rate of enrollment and investment in institutions.

6) Everything has its pros and cons. Not all aspects of Australian universities are better than that of Chinese universities. Only advantages which are useful and accordance with the situation of western Chinese universities can be used as reference. This should be further investigated.

\section{Acknowledgements}

The cooperation from the officers and staff members of the University of Adelaide, Flinders University and the University of Queensland providing the necessary permission to laboratory, classroom and so on is duly acknowledged. The support provided by Dr. Qing Hongyu, the senior lecturer of Flinders University is thankfully acknowledged. The support provided by Dr. Zhao Honghua, the associate professor of Dalian University of Technology and visiting scholar in the University of Adelaide is thankfully acknowledged.

The China Scholarship Council financially supported this paper.

\section{References}

[1] Australian Education Network, "List of universities in Australia," http://www.australianuniversities.com.au/list/ (accessed Oct 31 2016).

[2] QS, "QS World University Rankings ${ }^{\circledR} \quad$ 2016-2017," http://www.topuniversities.com/university-rankings/world-uni versity-rankings/2016 (accessed Oct 31 2016).

[3] Ministry of Education of PRC, "2016 names of the university in whole country," http://www.moe.gov.cn/srcsite/A03/moe_634/201606/t201606 03_248263.html (accessed June 3 2016).(in Chinese)

[4] Liu Q, Jiang YM. The Outcomes of Chinese Visiting Scholars Experiences at Canadian Universities: Implications for Faculty Development at Chinese Universities. Frontiers of Education in China, 2015, 10: 439-469.

[5] CSC, "2016 selection briefs for study abroad funded by National Study Abroad http://www.csc.edu.cn/article/280 (accessed Jan 4 2016). (in Chinese)

[6] Wang Y. Analysis on the management of university faculty in studying and exchanges abroad. Value Engineering, 2010, 29: 175-176.(in Chinese)

[7] Jing XZ, Zhang SS. Remarks on government-funded studying abroad programs at higher education institutions. Manager's Journal, 2014, 17: 220-220. (in Chinese)

[8] Liu J, Dai ZX. On the internationalization of higher education institutions in China. Higher Education Studies, 2012, 2:60-64.

[9] Wilkerson L, Irby DM. Strategies for improving teaching practices: a comprehensive approach to faculty development. Academic Medicine, 1998, 73: 387-396.

[10] Chen XF. The evolution and benefits of the policy for government-funded studying abroad since the reform and opening-up in China. Fudan Education Forum, 2004, 2: 12-16. (in Chinese)

[11] Leng P. University linkages and international development assistance: Lessons from the Canada-China experience. The International Journal of Comparative Education and Development, 2014, 16: 71-89. 
[12] Rhoads RA, Hu J. The internationalization of faculty life in China. Asia Pacific Journal of Education, 2012, 32: 351-365.

[13] Zhao HJ, An WG, Xu FF. Suggestions on studying abroad programs at local higher education institutions. Hebei Enterprise, 2014, 5: 42-42. (in Chinese)

[14] Williams R, Van DN. Research output of Australian universities: are the newer institutions catching up? Australian Universities' Review, 2010, 52: 32-36.

[15] Governor Business Solutions, "The advantages of smart boards in the classroom," http://www.governorsolutions.com/the-advantages-of-smart-b oards-in-the-classroom/ (accessed Mar 3 2014).

[16] Ministry of Education of PRC, "Action plan for the promotion of education in twenty-first century," http://www.moe.edu.cn/publicfiles/business/htmlfiles/moe/s69 86/200407/2487.html (accessed Dec 24 1998). (in Chinese)
[17] Ye XY, Ding YQ. Expanding Chinese Higher Education: Quality and Social Stratification. Chinese Journal of Sociology, 2015, 35: 193-220. (in Chinese)

[18] Wu XG. Higher Education, Elite Formation and Social Stratification in Contemporary China. hinese Journal of Sociology, 2016, 36: 1-31. (in Chinese)

[19] Xu J, Meng XC. A Study of the relation between the system of China's investment in higher education and the subject of imvestment. Journal of Shanghai University (Social Sciences), 2010, 17: 108-119. (in Chinese)

[20] Yan FQ, Zhuo XH, Yu J. System changes in China's massification of higher education. Journal of Higher Education, 2006, 27: 1-7. (in Chinese) 